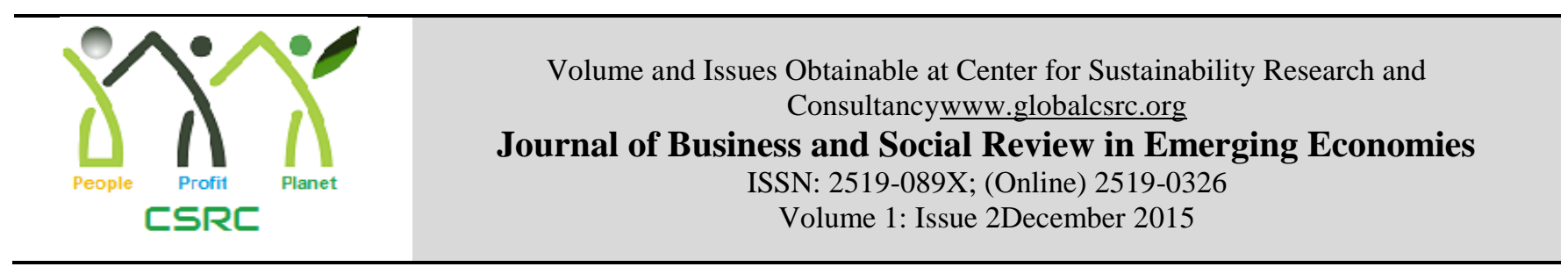

\title{
Tracing the Weaknesses of the Regulatory Framework for Clinical Trial in Nigeria
}

\author{
${ }^{1}$ Sani Ibrahim Salihu, ${ }^{2}$ Yuhanif Yusof, ${ }^{3}$ Rohizan Halim \\ ${ }^{1} \mathrm{PhD}$ Scholar, School of Law, Universiti Utara Malaysia \\ sisalihu.pcl@buk.edu.ng \\ ${ }^{2}$ Senior Lecturer, School of Law, College of Law, Universiti Utara Malaysia \\ yuhanif@uum.edu.my \\ ${ }^{3}$ Senior Lecturer, School of Law, College of Law, Universiti Utara Malaysia \\ rohizan@uum.edu.my
}

\begin{tabular}{l}
\hline ARTICLEDETAILS \\
\hline History \\
RevisedFormat: Nov2015 \\
AvailableOnline: Dec2015 \\
\\
\hline Keywords \\
Clinical Trial \\
Informed Consent \\
Ethics \\
Human Rights \\
\hline
\end{tabular}

JEL Classification:

O10, O15,

\begin{abstract}
Nigeria is one of the developing countries with a very weak and incomprehensive regulatory framework for clinical trials. Past abuses of human subjects in clinical trials and cases of negligence and outright fraud necessitate the need for a stronger legal framework. An outbreak of meningitis in Nigeria in 1996 led to clinical trial of Trovan Drugs by Pfizer, which left many of the research subjects seriously impaired. Some died while some suffered paralysis and brain damage. It was obvious Nigeria has a weak regulatory frame work from the incident that took place in the mentioned above at the Infectious Dieses Hospital (IDH) Kano. Available literatures have also shown that at the time of the trial in Kano, there was no ethics committee to ensure ethics review process and monitor the ongoing trial.

Objectives: This research aimed at examining the Nigerian regulatory framework to bring out its weaknesses. It will also examine the strength and weakness of the current regulatory agencies, and suggest better regulatory framework that will make Nigerians less vulnerable to manipulation and fraud in clinical trials.

Methodology: Library research is used to study both primary and secondary legal resources.

Finding: Lack of standard regulatory body and lack unified legal framework is the cause of failure to protect human subject in Nigeria.
\end{abstract}

(C) 2015 The authors, under a Creative Commons Attribution-

NonCommercial 4.0

\section{Introduction}

It is easier and cheaper for pharmaceutical companies to do their investigation in the developing countries for economic, social, political and legal reasons. Economically the cost is significantly

*Corresponding Author Email Address: sisalihu.pcl@buk.edu.ng

Recommended citation:Salihu, S.I., Yusof, Y., Rohizan, H. (2015). Tracing the Weaknesses of the Regulatory Framework for Clinical Trial in Nigeria. Journal of Business and Social Review in Emerging Economies, 1 (2) 7788. DOI: https://doi.org/10.26710/jbsee.v1i2.10 
reduced compare to Europe and America to about $60 \%$ when compared to other countries, such as United State (Murari, 2012). People in developed countries are zealous about human rights and fear of being harmed. Politically the developed countries create an impression to the world that they are in control of all diseases and the cure. Regrettably, developing countries have a very weak legal system that makes their citizens vulnerable. They prefer to do investigation in the developing world where there is least expensive and less burdensome regulatory environment in order to avoid litigation in case of injury to participants.

The methodology followed to make this research paper is a doctrinal methodology. The available literatures on the issue are examined, particularly international instrument regulating clinical trial and the municipal laws e.g. the constitution and other relevant laws. The Pfizer case in Kano clinical trial was considered as the basis for conducting the research to review the legal framework in order to strengthen it to save more life from the hands of unscrupulous foregn pharmaceutical Companies.

Clinical trials is a study of drugs that are still in development or have not yet been approved by the relevant food and drugs agency for the use being studied, is important considering the need for invention of new drugs for new diseases. European Union (EU) Clinical Trial Directive defines it as, an investigation to ascertain the efficacy or safety of a medicine in human subjects (Idigbe, 2014). The trial is conducted on new drugs to determine whether or not they are safe and effective. So, where the safety of human being is at risk, good and effective framework must be in place to ensure protection, which is why agencies, rules and guidelines are provided to ensure ethical conduct and compliance with good clinical practice, but where there is none or is inadequate all hands must be on desk to provide solutions.

Nigeria like other countries has a National Health Research ethics committee (NREC) which is a national body that advises federal ministry of health in respect of ethical issues regarding clinical research (Devid, 2015). The body is responsible for formulating guideline and standard for conduct of both human and animal research. It also has the task of registering and auditing of Nigeria Health Research Ethics Committees (National Health Act, 2014). Part of its function in 2014 NHREC issued a statement on the use of experimental drugs. During 2014 West Africa Ebola virus outbreak, It noted that bureaucracy and administrative requirement is limiting international shipping of biological samples during the Ebola outbreak(Aminu, et al. 2016).

\section{Conceptual Clarification of Terms}

This part intends to clarify some important concepts. Consent or informed consent, is a necessary requirement for any clinical trials involving human subject. It came about since the historical antecedent that happen during the Nazi period with some physician involved in a terrified act of disrespect to human dignity in the name of clinical research. Informed consent is a recognised human right under International Covenanting on Civil and Political Right (United Nation,1996). Clinical Trials involves scientific research or test of medicine before consumption to ensure safety of human being. This is regulated by food and Drugs Administrative bodies in Nigeria and US. National Agency for Food and Drugs Administration and Control (NAFDAC) is the body responsible for regulating clinical trials in Nigeria. There is also Health Research Ethics Committee (HREC) established to carry out oversight function in the conduct of the trials (Defazio, 2013). It works under NAFDAC. Clinical research involves Ethical conduct of the 
health personnel and the researchers themselves to ensure compliance of Morals, legal, political and social issues (Singer, 2008).

\section{Brief History of Clinical Trial in Nigeria}

Since the advent of colonialism, a clinical trial was not a new thing in Nigeria. There has been the existence of Rockefeller Foundation which initiated the Rockefeller Foundation Yellow Fever Commission for West Africa, called the Yellow Fever Commission in 1925. It built a research unit in Yaba, Lagos (Nwabueze, 2004). Although it was only the issue of consent that was considered, there was a question of ethics as one of the corner stone in every clinical trial around the world. Britain established in 1954 the West African Council for Medical Research for its colonies, which was serving for the British government as medical research centre for its colonies. The law that established it made no specific provision regarding the kind of research and no mention was made of ethical aspect of it. Thereafter, the University College Hospital was established in Ibadan 1953, twenty years after the Nigeria military government established Medical Research Council of Nigeria (MRC) which was established to conduct medical research in Nigeria (Nwabueze, 2004).

In 1977 the National Science and Technology Development Agency was created and saddled with the responsibility of scientific research and development. Although one may say there was progress regarding the establishment of research centres in Nigeria, but the question was how safe were the participants, was the regulation also progressing to ensure compliance with ethical conduct of research especially where the research subject is a human being?

\section{International Instrument Regulating Clinical Research}

International law regulating clinical trials can be traced back to the trial of doctors during Nazi period, popularly known as Nuremberg trial. Where after the Second World War twenty three of Nazi physicians were tried for organising and participating in a war crime and crime against humanity through medical experiment, where victims of war were subjected to turture(Nelson, 2012). Seven out of the Doctors were convicted executed, some were sentenced to term of prison and others were acquitted. This event produced the Nuremberg code in 1949 (Nelson, 2012). The most horrible among the violation of research ethics was freezing experiment to examine for hypothermia and also designed to cause death and posing experiment conducted to test and evaluate the effect of poison in food and bullets. If all these research were done with the informed consent of the participant it will have been a different case all together, although even that the question of disrespecting human dignity would have arose. The code provides about 10 principles required to be observed in any trial. Notable among them is the voluntary consent of the research participant which is the corner stone of any good clinical practice (Dowbiggin, 2013).

\subsection{Nuremberg Code}

The code came during the trial at Nuremberg after World War II was conducted by the International Military Tribunal. Where it provides some basic principles that every clinical trial shall comply with. Nuremberg Code was the first most important document in respect of clinical 
trial in the world (Evelyn, 1997). Its first principle is research participant should have legal capacity to give consent; they should have free opportunity to exercise free power of choice, without the intervention of any element of force, fraud, deceit, duress, overreaching, or other ulterior form of constraint or coercion; and should have sufficient knowledge and comprehension of the elements of the subject matter involved as to enable him to make an understanding and enlightened decision (Evelyn, 1997). This latter element requires that before the acceptance of an affirmative decision by the experimental subject they should be made known to him the nature, duration, and purpose of the experiment; the method and means by which it is to be conducted; all inconveniences and hazards reasonably to be expected; and the effects upon his health or person which may possibly come from his participation in the experiment (Evelyn, 1997).

\subsection{Declaration of Helsinki}

It is widely believed that Nuremberg left a lot of important issues regarding protection of human subject in a clinical research. Medical researchers created another form of guidelines to set ethical standard (Laughton, 2012). Helsinki Declaration was issued by the world Medical Association. One of the major differences it has with Nuremberg code is that it added the full explanation before a patient gives his consent. It also allowed consent to be given in representation capacity, especially where the patient may not be able to give consent. This is because in the Nuremberg code consent must be given by the patient himself, and that covered cases of children and unconscious adult. In the course of this paper we shall see how it becomes necessary to have consent in a written form and documented, having in mind the notorious case of Pfizer in 1996. Many countries including US adapted and incorporated the declaration into their clinical research regulation (Laughton, 2012). However, it must be noted that the declaration lack any binding principle and there is no procedure for enforcement or any mechanism. One of its major setbacks is that it was considered not universal enough to establish a claim under Alien Tort Claim Act in the United State (Abdullahi, 2009).

\subsection{Council for International Organisation of Medical Science (CIOMS)}

This council collaborating with the World Health Organisation (WHO) published its international ethics for biomedical research involving human subjects. This guideline is more specific and practical guidance concerning the Helsinki principles. In guideline 5 it provides for an elaborate condition to be satisfied before consent is considered valid (Council for International Organizations of Medical Sciences, 2002). That before requesting an individual's consent to participate in research, the investigator must provide information, in a language or another communication that the individual can understand: that he participate by limitation and he has the right to refuse the invitation and if at any time agrees to be part of the research he can withdraw at any time, these and many other conditions shall be fulfilled (Council for International Organizations of Medical Sciences, 2002)

The Nuremberg Code and the international Covenant on Civil and Political Right (CCPR) that talked about consent make no distinction regarding therapeutic and non therapeutic research, which by necessary implication means all require the need for consent. Although in therapeutic 
research there may be conflict of interest between the patient and the need to protect the larger society, the disease has to be cured for the larger public to be safe and that will be a necessity for the research. This fundamental deficiency means that therapeutic research have largely been ignored by the medical profession. By necessary implication Article 1 of the Code and Article 7 of CCPR (both addressing consent) would mean that consent would be necessary in both therapeutic and non therapeutic research. Another implication is that victims of accident who are unconscious or those who are mentally impaired cannot if no treatment available be subjected to new therapeutic measure that may save their lives. If this interpretation shall be upheld, it has the implication of excluding other victims these laws aim to protect.

The international framework is unable to solve the problems that exist within the biomedical fields of research. These Codes and Declarations, by their very nature, are non-binding instruments that guide the conduct of research, but they are useful in guiding state parties to promulgate a law to ensure protection of ethical violation. Pharmaceutical companies take advantage of this fact, some have asserted that part of the problem is not that there is too little international standard setting but that there is too much of it (Murari, 2012). But because they are not binding instrument, they cannot be enforced against physicians or the pharmaceutical companies. However, it is opined that issues arising in clinical trials are not limited to ethical concerns, but into the realm of international human rights law (Murari, 2012).

\section{Legal Framework for Clinical Research in Nigeria}

Every legislation, rule or regulation, is protecting, restricting an exercise of a defined right or violating the said right. Therefore, since these rights are enshrined in the constitution, any other law limiting or restricting its exercise must be in tune with the constitution. For example, people have rights to engage in all commercial activities like, buying and selling of drugs is a legitimate business which must not be left unregulated. So regulating it is a democratically justifiable law in Nigeria. The law regulating it has its roots from the constitution as a ground norm.(Constitution of the Federal Republic of Nigeria 1999) Particularly is within the personal liberty of an individual to consent to be a participant in a research or not.

National Agency for Food and Drugs Administration and Control (NAFDAC) is the principal regulatory body established by law (National Agency for Food and Drug Administration and Control Act, 2004). Although the main function of the Agency is regulating food and controlling drugs administration in Nigeria, the Agency also takes charge of regulating clinical trials by ensuring compliance with standard and to provide procedure and regulation for the trials. With a critical perusal of the functions of NAFDAC as provided under section 5, clinical trial is not an important segment of the agency. The agency dwell more on foods and drugs administration rather than clinical trial for drugs to ensure compliance with ethical standard in the process (Idigbe, 2014). The provision conferring the power to regulate food and drugs is too general and short of clarity. Although drugs legislation can cover either laws dealing with drugs specifically or cover both drugs and other substances, like cosmetics, food and beverages etc.(Jayasuriya, 1985) NAFDAC Act chooses to cover both, but without giving importance to clinical trial especially where human being is the subjects. Providing the authority is not enough. The powers and the functions must be clearly spelt out to avoid ambiguity. Good legal framework works to lessen casualties in a trial. 
Drugs labelling regulation (Erhun Babalola \& Erhun, 2001) provides that all tablets, capsule, caplet and similar on dosage form shall bear identification marks traceable to the manufacturer of holder of a certificate of registration of the product unless otherwise exempted by NAFDAC for the purpose of clinical trial investigation or bioequivalent studies. Drugs and Related Products (Registration) Decree No. 19 of 1993. These laws make provisions for the prohibition of the manufacture, importation, exportation, advertisement, sale or distribution of drugs, drug products, cosmetics or medical devices unless it has been registered in accordance with the provisions of the decree. It also stipulates the procedure for applying for registration of a drug product, conditions under which information supplied by an applicant is disclosed, and provisions for the suspension or cancellation of certificates of registration and clinical trials. Penalties for contravention of provisions of this decree are also stipulated therein. Lack of over sight function and regulatory framework put the society at risk in conducting clinical trial and research. People in Nigeria do not enjoy the right and protection enjoy by people in Europe and US (Postal \& Diaz, 2012). These laws are not adequate in protecting human subject in a clinical research.

In exercise of its powers under section 5 and 29,(National Agency for Food and Drug Administration and Control Act, 2004) NAFDAC issued Good Clinical Practice Regulation 2009 (Good Clinical Practice Regulations 2009). The regulation prescribed the requirement of good clinical trials in conducting clinical trials including multi-centre trials to ensure rights, safety and well-being of trial participants are protected and make the result of the trial credible. The rules provide for conditions to be satisfied before a trial can be acceptable, that is to say that ethics committee must give a favorable opinion about the trial prior to submission of an application to NAFDAC. And NAFDAC shall give authorization for the conduct of the trial. The regulation prohibits the use of human as trial participant save under exceptional cases (Good Clinical Practice Regulations 2009). One of the basic requirements is informed consent of the participant or the participant authorized representative. The regulation is a carbon copy of the Helsinki Declaration which has international recognition although with no binding principle.

Recently National Health Act was signed into law on October 31, 2014. The NH Act aimed at establishing a framework for the regulation, development and management of a national health system and Setting standards for rendering healthcare services in Nigeria. The Act provides for the establishment of a National Health Research Committee, with members to be appointed by the minister on recommendation of Health Research Institutions and related bodies in Nigeria. It is expected to promote health research by public and private health authorities and give health research agenda and resources problem focus and priority. Most importantly, Research on living persons must be conducted in accordance with guidelines from relevant authorities (CohenAlmagor, 2011). It must be complied with international standard, like written informed consent, if on minors, and only when it is in the best interest of the minor, or with the written informed consent of the parent or guardian. It also has the power to determine guidelines to be followed by health research ethics committees (HRECs): Set standards for conducting research on humans and animals including clinical trials. Determine the extent of health research to be carried out by health authorities (Cohen-Almagor, 2011).

It is mandatory that every clinical trial must comply with international ethics and scientific quality standard for designing, conducting and reporting trials that involve human participation. This is known as Good Clinical Practice (GCP) (Good Cliical Practice Regulatios 2005). Every country should have a good clinical practice standard. A guideline shall be provided to ensure 
compliance with Good Clinical practice regulation. NAFDAC issued a good clinical practice guideline in 2005 to ensure and maintain standard. If the guideline is complied with, the public shall be safe from injury resulting from clinical trial. ${ }^{1}$ However lack of monitoring and enforcement mechanisms make the guideline ineffective, although the guidelines described the responsibilities and expectations of all participants in the conduct of clinical trials, including investigators, monitors, sponsors and ethics committees.

\section{The National Health Research Ethics Committee (NHREC)}

The National Health Research Ethics Committee (NHREC) came into existence since October 2005 in order to strengthen mechanism that will ensure the protection of Nigerians participating in clinical research. The committee emanated from Health Research Ethics Committee which had been in existence since early 1980's, and had been able to come up with the National Code of Health Research Ethics (Famuyiwa, 2014).

The committee is to: (a) Set norms and standards for conducting research on humans and animals, including clinical trials among others; Adjudicate in grievances arising from the functioning of health research ethics committees and listen to any complaint of discrimination by any of the health research committees against a researcher; Refer to the relevant statutory health professional council, matters involving the violation or potential violation of an ethical or professional rule by a health care provider; Recommend disciplinary action as may be prescribed by law or permissible by law to the appropriate body against any person in deterrence or violation of any norms and standards, or guidelines, set for the conduct of research under this Act; and Appropriately advise the Federal Ministry of Health and State Ministries of Health on any ethical issues concerning research on health.

Before the establishment of National Code of Health Research Ethics in Nigeria, each institution has health research ethics committee based on international guidelines. Lack of uniformity will be seen as one of the problem. There was also no coordinating and legally binding enforcement mechanism. That is why research involving human is conducted in Nigeria without checks and proper scrutiny. In addition, there was no systematic and sustained development of a culture of ethical health research in national institutions. This is true because the notorious Pfizer case in Kano is illustrative. Investigation has shown that the document presented by Pfizer to go on with the research was forged (Abdullah, 2009). No penalty to serve as deterrent, even where one is provided is inadequate. for example, Where research is conducted with foreign funds, the only penalty in case of non- compliance with ethical standards was to extenuate such funding and extirpate such deterrent researchers from future funding from the same sources, but that did not translate to annihilation of funds from other research funds, and this coupled with absence of domestic legal regulation of ethical research. Above all, the difficulty of having a successful enforcement of ethical standards through litigation, partly because of weak judicial systems, the absence of enabling laws, and unenforceability of international guidelines such as the Nuremberg Code, Belmont principles, Helsinki Declaration, and Council for International Organization of Medical Sciences (CIOMS) guidelines. They are all described as non-legally binding declarative statements that lack the specificity required for legal action, they are therefore not legally enforceable and their contravention in developing countries carries minimal risk to researchers,

\footnotetext{
${ }^{1}$ NAFDAC Good Clinical Practice Guidelines 2015
} 
these aforementioned were then the cause of breach of ethical researches in Nigeria (Abdullah, 2009).

\section{Identifying the Weaknesses}

The regulatory framework for clinical trials available in Nigeria is inadequate to protect human subjects. It is obvious this is the reason why developing countries like Nigeria become centre of clinical research. Ethical issues in the course of the trials are not given the required attention. Even some of the agencies are not given the attention they need. For example Research Ethics Committee was there for ages, but with no attention given to them. In Nigeria the Ethics Committee was established since 1980, but the Code for Health Research Ethics was only issued in 2006 (Ademiluyi \& Aluko-Arowolo, 2009). And non compliance with ethical clearance by Pfizer in the Trovan trial in Nigeria is a clear cut example of the weakness of the regulatory agencies such as NHREC and NAFDAC (Ademabawo, 2007).

The legal framework is not harmonized. In Nigeria different institutions conduct clinical research under their enabling laws. The problem is that there will not be uniformity of regulation. For instance National Institute for Medical Research was established by virtue of the Research Institute (Establishment, etc) Order, a subsidiary legislation made pursuant to National Agency for Science and Engineering Infrastructure Act. To undertake medical research; University of Ibadan Act (Laws of the Federation of Nigeria,2004) establishes a post graduate School of Medical research. The implication of this is that these schools/institutes may conduct a clinical trial in the name of research without the approval of NAFDAC or NHREC and there may not be compliance with good clinical practices (Laws of the Federation of Nigeria 2004). This position used to be the case in America, with the enactment of what is now called "the Common Rule" which regulates any research funded by federal Government. This means that all other researches involving human subject are not regulated by the common rule. They are rather regulated by common or statutory laws governing day-to-day activities of human endeavor, e.g. Tort, contract and criminal law (Barbard, 2012). However, this created a problem for the system. There are regulated and unregulated researches involving human subject. In order to close the gap the new rule now extend to all research sponsored by a university regardless of whether the research is funded by government or not (Barnard, 2012). However this still left untouched research conducted by private investigators especially outside United State.

The newly passed National Health Bill provides for the establishment of Ethics committee in Nigeria.(National Health Act, 2014) It requires every Institution or Health Agency where research may be conducted to establish and have Ethics Committee which is registered with National Health Ethics Committee to review research and grant approval. However, because the framework is not good enough it is difficult to ensure compliance with this requirement.(C., 2008) There is no good monitoring to ensure compliance. Pfizer case can attest to this position, where Pfizer take advantage of the gap using special hospital in Kano. The trial was conducted without informed consent of the participants. Investigation revealed that even the permission of the ethics committee was forged (Andanda, 2011).

International efforts to protect human subject in clinical trial is not sufficient enough. Even the International Conference on Harmonization (ICH) that was established to create International Ethical Guidelines for Biomedical Research. The Declaration of Helsinki, CIOM and Nuremberg 
Code are all voluntary. They are not enforceable. Above all they are not recognized as international law under Alien Tort Claim Act (ATCA) (Famuyiwa., 2007).

None of the regulatory laws and instruments provides a remedy for victims or research participants. And where research participants wish to seek for remedy in court under common law, the rigorous procedure and difficulties in facing an international pharmaceutical company are enough challenges (Salihu, 2015).

Looking at the framework in other jurisdictions like US, it will do good for the Nigerian legal framework to be revisited. In US there is Food and Drugs Administration (FDA) as a body responsible for regulating clinical trials. It has the power to receive and consider any application for clinical research. FDA in collaboration with department of Health and Human Service (DHHS) adopted the so-called "Common Rule" with the aim of protecting human subject, apart from this law there are other laws, like Pediatric Research Equity Act 2003. It has also made a rule that all clinical trials conducted to secure FDA making authorization must adhere to 21 CFR part 50 and 56 which are regulation designed to project the right of human subject. The rules require protection of human subject who participate in clinical trial. FDA provides further guidance known as Informed Consent, ICH Good clinical practice (GCP). There is also an Institution Review Board. This is a clear evidence that Nigerian regulatory framework is weak, although US has gone far in term of both political and economic advancement, is not an excuse not to protect its citizens from any human right violation through clinical trial.

Therefore it is the suggestion of this writer that leave shall be borrowed from other jurisdiction to improve the situation.

\section{Conclusion}

The effort of the international community to protect human subject in a clinical trial has not yielded much result. The instruments are not enforceable. They are voluntary by their nature and they did not form part of customary international law to be enforceable under Alien Tort Claim Act. There has to be legislation in the US to recognise ICCPR and or Nuremberg Code as part of international law under Alien Tort Claim Act since Supreme Court and circuit court refused to do so. At the level of state the legal framework needs to be improved to protect human subject more. It is the suggestion of this writer that a suitable forum has to be established either by United Nation Enforcement Council or an independent tribunal and the council must recognise or accept corporations as legal persons in order to prosecute them. It is the government responsibility under international law to protect its citizens, therefore government has to stop considering the benefit it will get from foreign researchers and concentrate on the protection of its citizens. For Nigeria at least even if a separate body shall not be established for this purpose alone, there shall be mechanism for the enforcement of violation of the available rules.

\section{References}

2004, cap C. 23 laws of the federation of nigeria. Constitution of the federal republic of nigeria 1999, Pub. L. No. Cap C 232004 (1999). Nigeria. 
Ademiluyi, I. A., \& Aluko-Arowolo, S. O. (2009). Infrastructural distribution of healthcare services in Nigeria: An overview. Journal of Geography and Regional Planning, 2(5), 104110.

Aminu Yakubu1, Morenike Oluwatoyin Folayan2, Nasir Sani-Gwarzo3, Patrick Nguku4, Kristin Peterson5, B. B. (2016). The Ebola outbreak in Western Africa: ethical obligations for care. $J$ Med Ethics, 42.

C., O. (2008). Regulating Research Involving Human in Nigeria: Some Recent Improvement. Health Law Review, 16(4), 36.

Cir., (2d. Abdullahi v Pfizer (2009).

Cohen-Almagor, R. (2011). Physician-Assisted Suicide - A Qualified Endorsement. Health Care, Bioethics and the Law, 4, 116.

Council for International Organizations of Medical Sciences (2002). Geneva.

CR., N. (2012). Remembrance there is Prevention: A brief Review of four Historical Failures to Project human Subject. Journal of Reaserch and Administaration, VXLIII, 99.

Defazio G1, Hallett M, Jinnah HA, B. A. (2013). Development and validation of a clinical guideline for diagnosing blepharospasm. Neurology., 16(3).

Dowbiggin, I. (2013). From Sander to Schiavo: Morality, Partisan Politics, and America's Culture War over Euthanasia, 1950-2010. Journal of Policy History, 25(1), 12-41. http://doi.org/10.1353/jph.2013.0000

Erhun Babalola, W. O., \& Erhun, M. (2001). Drug Regulation and Control in Nigeria: The Challenge of Counterfeit Drugs. Journal of Health \& Population in Developing Countries, $4(2), 23-34$.

Etal, A. C. . (2007). Developing Ethical Oversight of Research IN Developing Countries: Case study of Nigeria. Harvard Health Policy Review Spring, 8, 96.

Etal, A. P. (2011). . The Ethical and Legal Regulation of HIV-Vaccine Research in Africa: Lessons from Cameroon, Malawi, Nigeria, Rwanda and Zambiya. African Journal of AIDS Research, 10(4).

Evelyn, S. (1997). Fifty Years Later: The Significance of the Nuremberg Code,". The New England Journal of Medicine, 337, 1436.

F., W. A. (2007). Closing the Constant Garden: The Regulation and Responsibility of U.S. Pharmaceutical Companies Doing Research on Human Subjects in Developing Nations. Washington University Global Studies Law Review, 6(3).

GOOD CLIICAL PRACTICE REGULATIOS 2009 C (2009). Nigeria.

Idigbe. (2014). Nigeria: Balancing Access to experimental Drugs with the Constitutional Right to life and the Legal imperative for strict enforcement and compliance with Clinical Trial Laws. Mondaq Connecting Knowledge and People.

J.S, B. (2012). Closing the Gaps in Human Subject Research Law: Regulating Clinical Research Conducted Outside the United State. Anal Health Law, 21(1).

Jan, B. M. \& M. (n.d.). Conducting Clinical Trial in the US and Abroad: Navigating the Rise Tide of Regulational Risk.

Jayasuriya, D. C. (1985). REGULATION OF PHARMACEUTICALS IN DEVELOPING COUNTRIES: Legal Issues and Approaches. WORLD HEALTH ORGANIZATION.

Laughton, A. H. (2012). Somewhere to Run, Somewhere to Hide? International Regulation of Human Subject Experimentation. Duke Journal of Comparative \& International Law, 18, 181.

M.K, F. (2014). Knowledge of Public Health Ethics among Medical Doctors in Nigeria: A Case 
Study. South American Journal of Public Health, 2(3), 475.

Murari, G. (2012). Clinical Research and its Condition in India. Journal of Clinical Research \& Bioethics, 4(2). http://doi.org/10.4172/2155-9627.1000146

N, D. A. (2015). Health Research in the National Health Act: Time for NIMR to Re-strategize in Response to National Health Research Priorities.

Nation, U. INTERNATIONAL COVENANT ON CIVIL AND POLITICAL RIGHTS (1996).

National Agency for Food and Drug Administration and Control Act (2004). Nigeria.

National Health Act (2014). Nigeria.

Nwabueze, R. N. (2004). Ethical review of research involving human subjects in Nigeria: legal and policy issues. Ind. Int'l \& Comp. L.Rev., 14.

Postal, S. W., \& Diaz, R. W. (2012). A Remedy in Sight : International Clinical Research Regulation. Journal of Environmental and Public Health Law, 6(1), 1-40.

Salihu, S. I. (2015). The Dilemma and Challenges in litigation by Victim of Human Rights Violation against Multinational Corporation". Nigerian Law School Bagauda Law Review. Singer, P. A. (2008). The Cambridge Textbook of Bioethics. New York: Cambridge University Press. http://doi.org/http://dx.doi.org/10.1017/CBO9780511545566

Wollensack A F., (2007). Closing the Constant Garden: The Regulation and Responsibility of U.S. Pharmaceutical Companies Doing Research on Human Subjects in Developing Nations. Washington University Global Studies Law Review, 6(3). 
